\title{
Pembentukkan Konsep Diri Beauty Vlogger Laki-Laki Dalam Instagram
}

\author{
Christivia HadiPutri, Ahmad Junaidi \\ Christivia.915150163@stu.untar.ac.id,Ahmadd@fikom.untar.ac.id
}

Fakultas Ilmu Komunikasi Universitas Tarumanagara

\begin{abstract}
Beauty vlogger is a term used for someone who shares beauty content through social media such as Instagram in form of videos or photos. As time goes by, this phenomenon is not only done by female, but also male have started to share their beauty content on social media Instagram. When male beauty vlogger upload a make up content, many responses are received from the followers or other users. This research is aimed to find out the development of male beauty vloggers on Instagram. Therefore, the theory used in this study is a self-concept theory. The method for this research is phenomenologi with descriptive qualitative approach. The data of this research are collected through in-depth interview with a few male who an beauty vlogger, observation non-participant and online data. Based on the results of this research, it is shown that other's image factors are shaped from parents' support, friends, and their followers on Instagram. Next, on social comparison factor, male beauty vloggers see their strength and weakness through comparing they do to their competitors. Other than that, on cultural factor, there are religious teachings or advices embraced by their parents then handed down to them. Lastly, there's self evaluation factor in which male beauty vloggers see that makeup is a positive thing and is in accordance with what they believe.
\end{abstract}

Keywords: Self-Concept, Social Media Instagram, Phenomenology

\begin{abstract}
Abstrak
Beauty vlogger merupakan sebutan untuk seseorang yang membagikan konten kecantikan di media sosial seperti Instagram dalam bentuk video maupun foto. Pada perkembangannya kini fenomena beauty vlogger tak lagi dilakukan oleh perempuan saja, tetapi laki-laki juga sudah mulai membagikan konten kecantikannya di media sosial Instagram. Adapun pada saat pengunggahan konten dilakukan, banyak yang memberikan respon dari pengikut maupun pengguna lainnya. Penelitian ini bertujuan untuk mengetahui pembentukkan konsep diri seorang beauty vlogger laki-laki di media sosial Instagram, sehingga teori yang digunakan adalah teori konsep diri. Metode yang digunakan adalah metode fenomenologi dengan pendekatan kualitatif deskriptif. Adapun metode pengumpulan data yang menggunakan wawancara mendalam dengan beberapa beauty vlogger laki-laki, observasi tanpa partisipasi langsung dan data online. Kesimpulan dalam penelitian ini adalah faktor citra orang lain yaitu, dukungan dari orangtua, teman-teman, serta para pengikutnya di Instagram. Selanjutnya dalam faktor perbandingan sosial, beauty vlogger laki-laki melihat kelemahan dan kelebihannya melalui perbandingan yang mereka lakukan dengan kompetitornya. Selain itu, dalam faktor ajaran budaya, ada ajaran agama atau petuah-petuah yang dianut oleh orang tuanya dan diturunkan kepada para beauty vlogger lak-laki Kemudian faktor yang terakhir, yaitu faktor evaluasi diri, beauty vlogger laki-laki melihat bahwa makeup ini merupakan hal yang positif dan sesuai dengan apa yang mereka yakini.
\end{abstract}

Kata Kunci: Konsep Diri, Media Sosial Instagram, Fenomenologi 


\section{Pendahuluan}

Perkembangan teknologi yang semakin canggih dan cepat memudahkan manusia dalam melakukan aktivitas, yang meliputi mengakses informasi, berita, hiburan maupun menjadi pelaku penyebaran informasi dan melakukan interaksi melalui media baru yaitu Internet. Romli dalam Azeharie mengatakan bahwa media sosial digunakan oleh para pengguna untuk menciptakan dan berbagi pesan ke dalam jejaring sosial maupun dunia virtual, dengan hal tersebut, Romli mengajak semua orang untuk ikut serta dalam memberikan kontribusi dan memberikan feedback secara terbuka, serta berbagi informasi apa saja, ,dimana saja dan kapanpun dengan kecepatan penyebaran yang hanya dalam hitungan detik (Azeharie, 2015).

Hadirnya media sosial seperti Facebook, Twitter, Youtube, Whatsapp dan Instagram tiap tahunnya mengalami perkembangan dan kenaikan pengguna. Indoneaia menduduki peringkat ke-3 sebagai pengguna aktif media sosial saat ini dengan persentase $23 \%$.

Gambar 1. Pertumbuhan Pengguna Sosial Media di Berbagai Negara

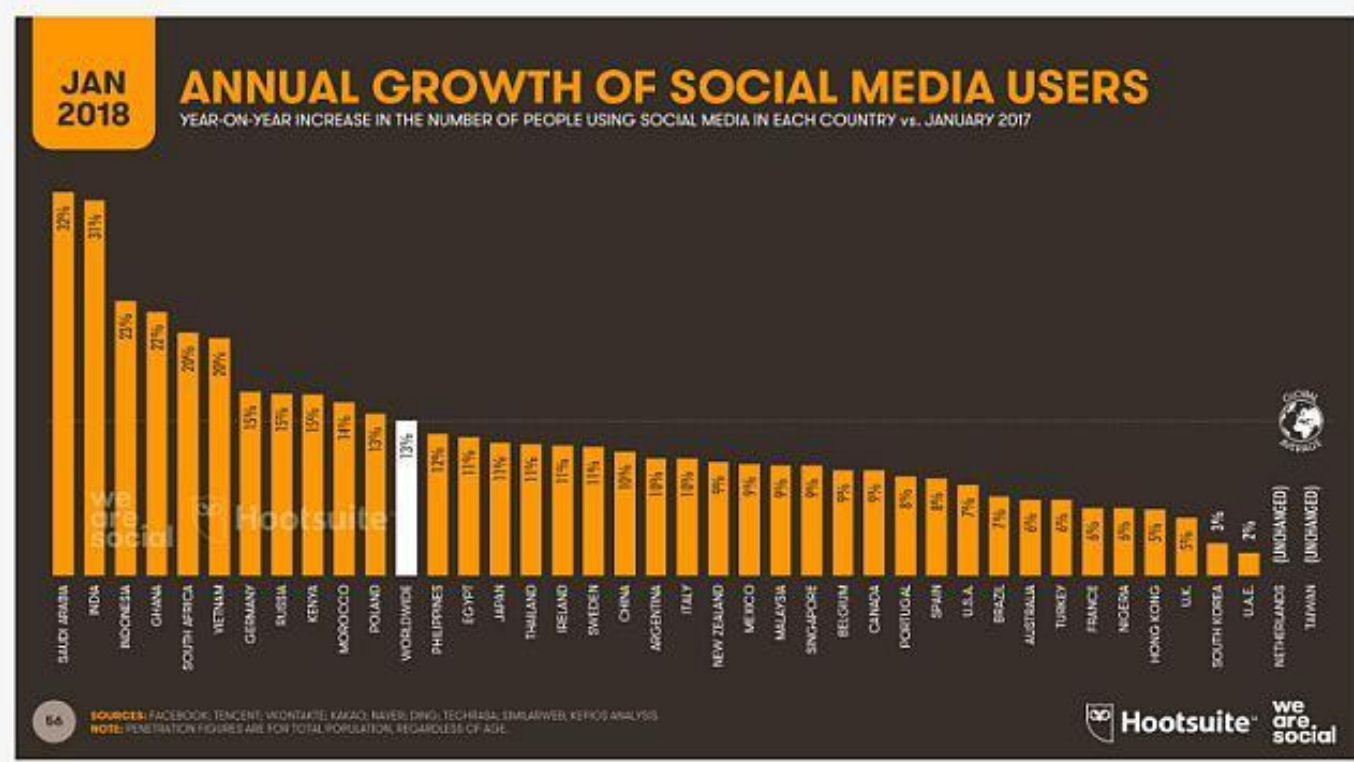

Sumber: https://wearesocial.com/blog/2018/01/global-digital-report-2018, diakses pada tanggal 28/08/18 pukul 13.15 WIB

Sementara untuk pengguna aktif media sosial Instagram di Indonesia, berdasarkan data statistik We Are Social pada Januari 2017 menduduki peringkat ke3 dengan perolehan 39\% (https://www.slideshare.net/wearesocialsg/digital-in-2017southeast-asia , diakses pada tanggal 28/08/18 pukul $13.10 \mathrm{WIB}$ ), walaupun pada Januari 2018 ini sempat menjadi urutan ke-4 karena di susul oleh whatsapp, nyatanya instagram masih diminati oleh para pengguna internet.(https://www.slideshare.net/wearesocial/digital-in-2018-in-southeast-asiapart-2-southeast-86866464, diakses pada tanggal 28/08/18 pukul 13.15 WIB)

Beauty vlogger merupakan sebutan untuk para pembuat konten berupa video yang fokus pada dunia kecantikan (Fitriah \& Sakari, 2017). Vlog merupakan bentuk publikasi online yang memungkinkan semua orang terhubung dengan akses web dan peralatan video sederhana seperti telepon genggam dan komputer (Molyneaux,et all.,2007 dalam Haryanto 2017) dan merupakan kegiatan personal pada Youtube. 
Walaupun konten vlog lebih banyak di Youtube, namun perkembangannya disini sudah mulai merambah kepada Instagram, dan persentasenya juga tidak kalah tinggi. Terbukti dari survei internal yg dilakukan Jasa All Sosmed pada 2017 lalu, videogram dan fashion style menduduki posisi $2 \& 3$ dengan presentase $60 \%$ dan $45 \%$ dalam kategori konten paling diminati pengguna media sosial aktif Instagram di Indonesia. Hal tersebut membuktikan bahwa pengguna aktif media sosial Instagram di indonesia menikmati konten berisi fashion style dan videogram.(https://jasaallsosmed.co.id/services/instagram/follower , diakses pada tanggal 20/09/18 pukul 22.01 WIB)

Fenomena penggunaan makeup, ternyata tidak hanya terjadi pada para perempuan saja, nyatanya saat ini banyak pria yang dalam kesehariannya dan dalam postingan media sosialnya, seperti di Instagram, mengunggah foto atau video dengan menggunakan makeup. Adapun dari mereka yang menjadi beauty vlogger karena mereka juga membagikan konten kecantikan seperti Endi Feng, Alpha Make Up, Jihan Delano, Florenzio, dan lainnya, dalam bentuk tutorial, review kosmetik dan foto hasil makeup look-nya di Instagram sebagai referensi untuk pengguna lain yang merupakan penggemar kecantikan. Beauty vlogger biasanya identik dengan perempuan, hal tersebut berbanding lurus dengan nilai-nilai yang berada di masyarakat yang mengasosiasikan konsep cantik dan gender perempuan (Haryanto, 2017:1). Menurut Kementerian Industri Republik Indonesia, industri komestik nasional tercatat mengalami kenaikan pertumbuhan mencapai $20 \%$ atau empat kali lipat dari pertumbuhan ekonomi nasional pada tahun 2017. Membuktikan bahwa, konsumsi kosmetik sedang digemari oleh masyarakat, terutama para perempuan dan sudah menjadi kebutuhan primer. Adapun pada perkembangannya kini, industri kosmetik juga berinovasi pada produk kosmetik untuk pria dan anakanak.(http://www.kemenperin.go.id/artikel/18957/Industri-Kosmetik-Nasional-

Tumbuh-20, diakses pada tanggal 19/9/2018 pukul 16.00 WIB)

Unggahan foto maupun video di media sosial Instagram, mengenai kecantikan yang dilakukan oleh para laki-laki tak jarang menimbulkan berbagai pro kontra bagi para pengguna lainnya yang melihat konten tersebut. Ada orang-orang yang berkomentar negatif dan ada pula yang berkomentar positif untuk mendukung beauty vlogger agar semakin maju dalam pembuatan konten-konten kecantikan. Dari komentar-komentar tersebut bisa menjadi sebuah faktor dalam pembentukan konsep diri seorang beauty vlogger. Bastaman (2005) dalam Maharani mengatakan, konsep diri atau citra diri yang positif akan mewarnai pola sikap, cara pikir, corak penghayatan, dan ragam perbuatan yang positif pula, begitu juga dengan sebaliknya, apabila konsep dirinya negatif maka pola sikap, cara pikir, corak penghayatan, dan ragam perbuatannya akan negatif (Maharani, 2010). Hal tersebut berdampak dalam proses pembentukkan konsep dirinya. Adapula faktor dari keluarga dan idola yang membuat laki-laki tersebut ingin melakukan apa yang dilakukan oleh mereka, dalam hal ini ialah penggunaan makeup. Hal-hal tersebut merupakan faktor-faktor yang bisa membantu dalam pembentukan konsep diri seseorang. Maka dari itu tujuan dari penelitian ini adalah untuk mengetahui pembentukkan konsep diri seorang beauty vlogger laki-laki di Instagram.

\section{Metode Penelitian}

Pendekatan yang digunakan dalam penelitian ini adalah pendekatan kualitatif deskriptif. Menurut Bogdan dan Taylor, metodologi kualitatif dikatakan sebagai 
prosedur penelitian yang menghasilkan data deskriptif berupa kata-kata tertulis atau lisan dari orang-orang dan perilaku yang dapat diamati (Moleong, 2012). Penelitian kualitatif yang dikemukakan oleh Banister et al., yaitu metode untuk mengungkap dan memberikan gambaran terhadap suatu fenomena, sebagai metode untuk mengeksplorasi fenomena dan untuk memberikan pejelasan dari suatu fenomena yang diteliti (Herdiansyah, 2010).

Sementara metode yang digunakan dalam penelitian ini adalah metode fenomenologi. Secara sederhana, fenomenologi lebih memfokuskan diri pada konsep suatu fenomena tertentu dan bentuk dari studinya adalah untuk melihat dan memahami arti dari suatu pengalaman individual yang berkaitn dengan suatu fenomena tertentu.Fenomenologi berusaha mengungkap dan mempelajari serta memahami suatu fenomena beserta konteksnya yang khas dan unik yang dialami oeh individu hingga tataran "keyakinan" individu yang bersangkutan. Model fenomenologi fokusnya adalah kepada pengalaman yang dialami oleh individu, bagaimana individu memaknai pengalamannya tersebut berkaitan dengan fenomena tertentu yang sangat berpengaruh dan sangat berarti bagi individu yang bersangkutan. Pengalaman tersebut bukanlah pengalaman biasa, melainkan pengalaman yang berkaitan dengan struktur dan tingkat kesadaran individu (Herdiansyah, 2010).

Teknik pengumpulan data dalam penelitian ini dilakukan dengan wawancara mendalam bersama subjek penelitian yakni keempat narasumber yang merupakan beauty vlogger laki-laki yang meliputi Natta Fierce (Medan), Florenzio Opitta (Surabaya), Yudhistira El Vedayadi (Jember), dan Nanda Galih (Malang) melalui telepon, tatap muka dan e-mail terkait dengan objek penelitian ini yakni pada faktor pembentukkan konsep dirinya. Dalam penelitian ini penulis juga mewawancarai pakar ahli yang bernama Nukman Luthfie sebagai pakar media sosial melalui tatap muka. Adapun penulis juga melakukan pengamatan dari kegiatan para beauty vlogger di media sosial Instagram dan mengambil beberapa gambar-gambar sebagai bahan dokumentasi. Sementara teknik analisis data yang digunakan dalam penelitian ini ialah teknik Miles dan Huberman dengan cara mereduksi data mentah dari hasil wawancara mendalam bersama keempat key informan dan juga satu informan pakar hingga tahap penarikan kesimpulan. Serta dalam keabsahan data, penulis melakukan triangulasi sumber dalam penelitian ini.

\section{Hasil Temuan dan Diskusi}

Berdasarkan hasil penelitian yang dilakukan oleh peneliti dengan keempat key informan, yang merupakan beauty vlogger, ditemukan bahwa arti makeup adalah sebuah bagian dari seni yang bedanya canvas yang digunakan adalah wajah dan siapa saja bisa menggunakannya tanpa harus memandang gender. selain itu, dengan makeup ini mereka juga menemukan diri mereka yang sebenarnya. Temuan lainnya yakni, karena beberapa dari mereka dulunya menjadi seorang dancer, dimana pada saat menari diperlukan tampilan wajah yang menarik sesuai dengan karakter tariannya, sehingga akhirnya memutuskan untuk belajar makeup. Adapula yang berawal dari keisengan karena melihat teman-temannya menggunakan makeup dan keinginan untuk merapikan bentuk alis alhasil berujung pada penggunaan kosmetik lainnya, dan ada juga yang memilih makeup karena ingin mengasah kreativitas lebih lagi.

Dalam kesehariannya para beauty vlogger laki-laki menggunakan makeup pada acara-acara tertentu saja, seperti acara launching kosmetik maupun hangout dengan teman-teman. Berbeda dengan lainnya, salah satu key informan yang bernama Natta 
Fierce, mengatakan bahwa penggunaan makeup hanya untuk keperluan membagikan konten makeup di Instagram saja, diluar itu, ia enggan menggunakan makeup.

Selain itu, dalam temuan lainnya, media sosial Instagram dijadikan sebagai pencarian referensi makeup dengan hashtag tertentu dan wadah oleh para key informan untuk membagikan konten makeup-nya dalam bentuk video maupun foto karena exposure yang didapatkan bisa lebih banyak dan mudah dibanding dengan penyebarannya di Youtube. Serta ingin mendorong para laki-laki yang mungkin memiliki passion di bidang kecantikan agar termotivasi untuk percaya diri dan juga ingin menghilangkan pandangan masyarakat mengenai laki-laki yang ber-makeup.

Kegiatan makeup yang dilakukan oleh beauty vlogger laki-laki di media sosial Instagram merupakan bentuk dari pengekspresian dirinya dalam sisi feminitasnya, sesuai dengan pengertian makeup menurut para informan. Lebih lanjut, bentuk dari ekspresi gender di dalam riasan wajah yang mereka lakukan juga terdiri dari berbagai macam meliputi makeup natural, bold, membuat ulang riasan wajah seseorang, membuat makeup karakter dan juga terfokus pada permainan warna yang berani di matanya, seperti hijau, ungu dan warna berani lainnya yang mereka tunjukkan ke dalam format video maupun foto, yang kemudian di unggah melalui Instagram. Dengan demikian, Instagram menjadi sebuah wadah untuk membagikan konten makeup, sesuai dengan fungsi dari Instagram, yakni fungsi sharing.

Gambar 2. Ragam Makeup Beauty Vlogger Laki-laki

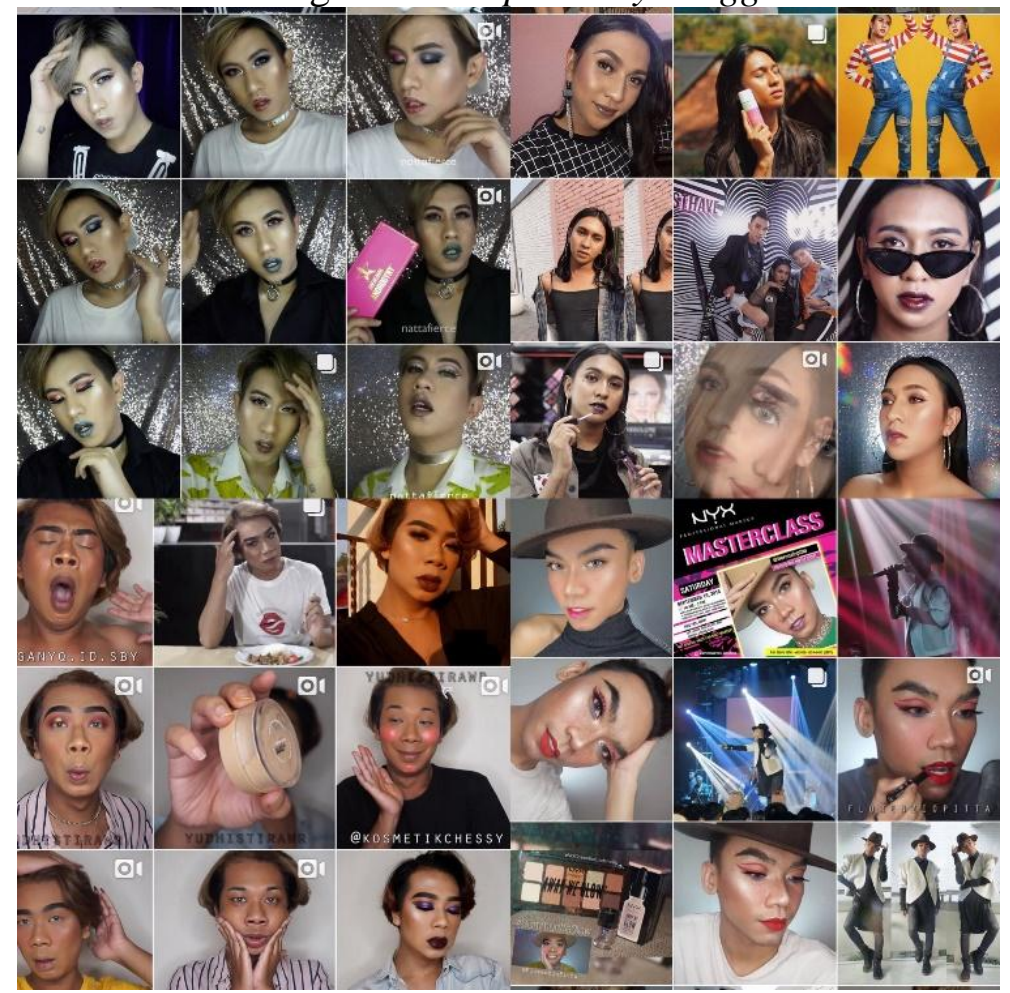

Sumber: Instagram.com/(@natta.fierce, @nandagalih, @yudhistirawr, @florenziopitta)

Hadirnya para beauty vlogger laki-laki di media sosial Instagram, menurut pakar media sosial Nukman Luthfie merupakan hal yang baik, karena menurutnya beauty itu bukanlah gender, dan laki-laki juga butuh hal-hal berbau kecantikan. Menurutnya, apa yang dilakukan oleh beauty vlogger laki-laki merupakan sebuah kreativitas dan bisa mendorong perekonomian negara dalam bidang kosmetik. 
Sesuai dengan teori yang dibahas dalam penelitian ini, faktor-faktor dalam pembentukan konsep diri, mengacu pada buku Devito (2012) yang berjudul The Interpersonal Communication Book, di mana sumber dalam pembentukkan konsep diri terdiri dari empat faktor yakni: citra orang lain, perbandingan sosial, ajaran budaya dan evaluasi diri (Devito, 2012).

Pertama, citra orang lain: bagaimana orang lain memperlakukan dan bereaksi terhadap dirinya (Devito, 2012). Orang lain disini meliputi kerabat dekat seperti teman, keluarga, para pengikut di Instagram, hingga idola (Rakhmat, 2011). Dukungan orang tua menjadi salah satu faktor dalam pembentukkan konsep diri seorang beauty vlogger laki-laki. Walaupun awalnya mereka tidak menyetujui apa yang dilakukan oleh anaknya, karena mereka merasa bahwa makeup merupakan hal yang biasa dilakukan perempuan, tapi beauty vlogger laki-laki ini membuktikkan nya dengan karya-karya positif serta berprestasi, akhirnya orang tua mendukung apapun pekerjaan atau kegiatan yang dijalani oleh anaknya. Sementara dukungan dari teman-teman dan para pengikut di Instagramnya, tak jarang juga masih ada yang menganggap bahwa apa yang dilakukan oleh beauty vlogger laki-laki ini merupakan kegiatan yang salah dan bahkan ada yang meminta beauty vlogger laki-laki ini untuk berhenti di dunia makeup. Namun ada juga yang mendukung untuk tetap berkarya dan juga memberikan saransaran seputar produk kosmetik maupun saran lainnya dan para beauty vlogger tersebut juga tetap menghargai kritik maupun saran yang diberikan orang lain, tetapi ia tetap kembali kepada keyakinannya dan pendiriannya. Selain itu tiap-tiap beauty vlogger laki-laki ini tentunya memiliki sosok seseorang yang mereka gemari, karena merasa banyak pelajaran yang bisa di ambil dari para idolanya tersebut, serta menjadikan idola sebagai referensi riasan makeup yang biasa mereka lakukan.

Kedua, faktor perbandingan sosial, bagaimana seseorang membandingkan dirinya terhadap orang lain (Devito, 2012). Pada faktor ini, sebagai manusia tentunya pernah merasakan rasa iri hati melihat beauty vlogger lainnya berkembang lebih cepat dan memiliki kemampuan yang lebih darinya, yang akhirnya membuat mereka mencoba untuk mengikutinya dan ternyata hasilnya gagal. Dari situ mereka menyadari bahwa keahlian atau kemampuan mereka hanya bisa di hal tertentu saja dan justru para beauty vlogger laki-laki saling mendukung, serta memberikan masukkan satu terhadap satu sama lain.

Faktor ketiga, yakni faktor ajaran budaya adalah bagaimana orang tua maupun kerabat dekat memberikan nilai-nilai, sikap dan kebudayaan yang ditanamkan kepada diri seseorang (Devito, 2012). Di sini ajaran atau petuah-petuah dari orang tua yang diturunkan kepada beauty vlogger laki-laki, yang tiap orangnya memiliki petuah yang berbeda-beda. Yudhi, salah satu informan dalam penelitian ini mengatakan bahwa ayahnya mengajarkan untuk jangan mengambil rejeki orang lain. Oleh sebab itu, ketika beauty vlogger lain lebih berhasil dan memiliki banyak pekerjaan dari padanya, maka Ia harus lebih bersabar dan mungkin memang bukan saatnya untuk mendapatkan pekerjaan tersebut. Adapula Florenzio mengatakan bahwa omanya mengajarkan sesuai dengan agama yang dianut untuk selalu bersyukur terhadap talenta yang diberikan oleh Tuhan dan manfaatkan talenta tersebut dengan hal-hal yang positif.

Faktor terakhir, yaitu faktor evaluasi diri adalah bagaimana seseorang melihat apa yang dilakukannya ini sesuai dengan yang dianut oleh budaya internalnya atau tidak, apabila sesuai, maka akan berdampak positif (Devito, 2012). Para beauty vlogger disini menganggap bahwa makeup ini merupakan hal yang mereka sukai saat ini dan merasa bahwa makeup ini merupakan passionnya. Ketika orang tua, kerabat dekatnya memberikan larangan untuk tidak melakukan hal ini (makeup), maka mereka 
membuktikkannya dengan cara mengikuti berbagai kompetisi makeup seperti $N Y X$ Face Awards, kompetisi-kompetisi kecil yang ada di Instagram dan juga dari beauty vlogger ini, mereka menghasilkan uang.

\section{Simpulan}

Kesimpulan dalam penelitian ini adalah faktor citra orang lain yaitu, dukungan dari orangtua, teman-teman, serta para pengikutnya di Instagram. Selanjutnya dalam faktor perbandingan sosial, beauty vlogger laki-laki melihat kelemahan dan kelebihannya melalui perbandingan yang mereka lakukan dengan kompetitornya. Selain itu, dalam faktor ajaran budaya, ada ajaran agama atau petuah-petuah yang dianut oleh orang tuanya dan diturunkan kepada para beauty vlogger lak-laki Kemudian faktor yang terakhir, yaitu faktor evaluasi diri, beauty vlogger laki-laki melihat bahwa makeup ini merupakan hal yang positif dan sesuai dengan apa yang ia yakini.

\section{Ucapan Terima Kasih}

Ucapan terima kasih diberikan kepada Fakultas Ilmu Komunikasi Universitas Tarumanagara dan juga kepada para narasumber yaitu: Natta Fierce , Florenzio Opitta, Yudhistira El Vedayadi, Nanda Galih dan Nukman Luthfie yang telah meluangkan waktunya dan bersedia menjadi narasumber, serta semua pihak yang telah mendukung dan membantu dalam penelitian ini.

\section{Daftar Pustaka}

A Devito, Joseph. (2012). The interpersonal communication book thirteenth edition. Pearson Education

Azeharie, S., \& Sari, W. (2015). Penyingkapan Diri Ibas Yudhoyono Dalam Instagram Dan Reaksi Ani Yudhoyono Terhadap Postingan Instagram Ibas. Jurnal Komunikasi, 7(1), 108-117.

Fitriah, Lestari \& Sakari, Gufron. 2017. Pemanfaatan Media Sosial Youtube yang digunakan Beauty Vlogger dalam mengedukasi Viewer : Jurnal Komunikasi, 1(2), 1\&24, diakses pada tanggal 20/9/2018 pukul 21.12

Haryanto, Nurul. 2017. Konstruksi Identitas Gender Beauty Vlogger Laki-laki pada Youtube : Jurnal Fakultas Ilmu Sosial dan Ilmu Politik. 1-3. http://repository.unair.ac.id/69243/3/JURNAL_Fis.K.11\%2018\%20Har\%20k.p df ,diakses pada tanggal 5/9/18 pukul 19.00 WIB.

Herdiansyah, Haris. (2010). Metodologi penelitian kualitatif. Salemba Humanika.

Jasa All Sosmed. (2018). Instagram Follower. < https://jasaallsosmed.co.id/services/instagram/follower>, diakses pada tanggal 20/09/18 pukul 22.01 WIB.

Kemenperin. (2018). <http://www.kemenperin.go.id/artikel/18957/IndustriKosmetik-Nasional-Tumbuh-20> , diakses pada tanggal 19/9/2018 pukul 16.00 WIB.

Maharani, Diah P. 2010. Konsep Diri Anak Jalanan : Jurnal Sosial dan Humaniora. 3.http://digilib.uinsuka.ac.id/5312/1/BAB\%20I\%2C\%20V\%2C\%20DAFTAR\%20PUSTAKA.pd f (Diakses pada 3/10/18 pada pukul 13.30 WIB. 
Moleong, Lexy J. (2012). Metodologi penelitian kualitatif. Bandung: PT Remaja Rosdakarya.

Rakhmat, Jalaluddin. (2011). Psikologi komunikasi. Bandung: PT Remaja Rosdakarya.

We Are Social. (2018). Digital in 2017 in Southeast Asia. <https://www.slideshare.net/wearesocialsg/digital-in-2017-southeast-asia>, diakses pada tanggal 28/08/18 pukul 13.10 WIB.

We Are Social. (2018). Digital in 2018 in Southeast Asia. <https://www.slideshare.net/wearesocial/digital-in-2018-in-southeast-asia-part2-southeast-86866464>, diakses pada tanggal 28/08/18 pukul 13.15 WIB.

We Are Social. (2018). Global Digital Report 2018. <https://wearesocial.com/blog/2018/01/global-digital-report-2018>, diakses pada tanggal 28/08/18 pukul 13.15 WIB. 